\title{
Neurotracker Training to Improve Shooting Performance of Archery Athletes
}

\author{
Komarudin*, Yusuf Hidayat, Geraldi Novian \\ Faculty of Sport and Health Education, Universitas Pendidikan Indonesia, Bandung, Indonesia
}

Received May 9, 2021; Revised June 16, 2021; Accepted July 22, 2021

\section{Cite This Paper in the following Citation Styles}

(a): [1] Komarudin, Yusuf Hidayat, Geraldi Novian, "Neurotracker Training to Improve Shooting Performance of Archery Athletes, "International Journal of Human Movement and Sports Sciences, Vol. 9, No. 4A, pp. 66 - 70, 2021. DOI: 10.13189/saj.2021.091311.

(b): Komarudin, Yusuf Hidayat, Geraldi Novian (2021). Neurotracker Training to Improve Shooting Performance of Archery Athletes. International Journal of Human Movement and Sports Sciences, 9(4A), 66 - 70. DOI: 10.13189/saj.2021.091311.

Copyright $\odot 2021$ by authors, all rights reserved. Authors agree that this article remains permanently open access under the terms of the Creative Commons Attribution License 4.0 International License

\begin{abstract}
Nowadays, there are a number of non-conventional training methods utilizing science and technology that can improve athlete performances, one of them is NeuroTracker technology. In Indonesia, this technology is still limited. Meanwhile, in developed countries, this method is developing rapidly and implemented for gaining sport achievements, including in archery. In archery, athletes must focus on performing techniques consistently, be fast, and be precise in making decisions when aiming and releasing arrows. In this condition, athletes often experience disturbances and doubts in aiming and releasing arrows so that the shooting performance is often not optimal. To overcome this problem, NeuroTracker technology can be provided in the training process to improve the archery athlete shooting ability. The method of this research used the experimental method with pretest-posttest control group design. The population of this study consisted of 40 archery athletes of one of the campus sports clubs. Samples were selected using non-random sampling to obtain 20 athletes. The samples were divided into two groups, including the experimental group and control group. The experimental group received NeuroTracker trainings, while the control group received the conventional trainings. The instrument used to measure the archery shooting ability was the $30 \mathrm{~m}$ shooting test. The results showed that NeuroTracker training and conventional training had a significant effect on the archery athlete shooting performance. Furthermore, NeuroTracker training had a greater effect than conventional training on the archery athlete shooting
\end{abstract}

performance.

Keywords Archery Athletes, Neurotracker, Shooting Performance

\section{Introduction}

Achievement in archery is determined by environment and physical, technical, tactical, psychological, and cognitive abilities. Psychological abilities are important for achieving the peak performance [1], especially for archery athletes. Archery athletes must have a psychological maturity because they must face psychological challenges in performing their duties in both training and competition situations. Archery athletes who are psychologically mature will be able to control all problems, have more confidence in their abilities, and have a commitment to do their job well [2].

Archery athletes in a competition, especially in shooting, are always influenced by various disturbances. Study of Lee \& De Bondt [3] emphasized that the interference could come from the opponents, teammates, coaches and/or managers, people to impress, viewers, cell phones, children crying, family or relationship issues, media journalists-photographers, video cameras, broadcasters, errors, unexpected high performance, unfavorable weather conditions, changing competition schedules, etc. These disturbances affect the shooting performance of archery athletes. To overcome various 
disturbances, athletes must be psychologically mature so that they will be able to optimize their potential during the training and competition processes [2]. Therefore, in improving psychological maturity, proper training methods utilizing science and technology are needed, namely the NeuroTracker training method. NeuroTracker technology is a product of neuro-Science research to improve an athlete performance. NeuroTracker training in Indonesia has not been widely known by coaches and athletes. On the other hand, in developed countries, especially in Europe, it is growing rapidly so that it is natural that sports in the country had achieved two world records, including in the Asian Games on the mixed team compound number at a 50 meter distance and in the mixed recurve team number at a 70 meter distance in the European Grand Prix in Bulgaria [4].

Archery athletes must have the ability to focus while performing archery techniques starting from doing the stance, nocking the arrow, hooking and gripping the bow, mind setting, setting up, drawing, anchoring, loading/transferring to holding, aiming and doing expansions, releasing, following through, and doing a feedback [3]. Therefore, the consistency and efficiency in archery could be well achieved. In addition, archery athletes must be able to make quick and precise decisions when aiming and releasing arrows so that the level of consistency is achieved. If the decision making is slow during shooting, especially in holding to release phases, the arm muscles will be tired quickly. The tired condition experienced by the athletes has an impact on the athlete's psychological condition. Study explains that the time needed to release the arrow is around 4-6 seconds, meaning that the shooting duration from the holding to release phase is the ideal time to release the arrow to get an optimal impact on the target [5]. Furthermore, another study explained that the shooting duration, from the holding phase to the release, between 1-3 seconds and 4-6 seconds had a significant effect on archery performance at a $30-$ meter distance. However, the 4-6 second shooting duration is better than the 1-3 second duration for archery achievement at a 30 meter distance [5].

The doubt in aiming and releasing the arrow will adversely affect the shooting performance. Usually, arrow grouping is difficult to be achieved in this condition. Therefore, the athletes should concentrate and quickly make decisions when shooting. For this reason, NeuroTracker technology is appropriate to be applied in the training process. This technology could combine awareness, attention, and focus, which can increase neuroplasticity in the brain, so that the athletes have the ability to adapt and change themselves to respond to the performance demands [6]. Therefore, the researchers were interested in further examining the effect of training using NeuroTracker technology on the archery athlete shooting performance.

\section{Research Method}

This study used an experimental method with a pretest-posttest control group design [7]. The population of this research consisted of 40 archery athletes in a sport club from a state university in Indonesia. To obtain 20 samples, the sampling technique used was the non-random sampling, namely purposive sampling. Samples were selected based on two considerations, including having shooting skills and participating in various archery competitions. Furthermore, the 20 subjects were divided into two groups through the random assignment technique. The groups included the experimental group and the control group, each of which consisted of 10 subjects. The experimental group in this study received the training using NeuroTracker technology, while the control group received the conventional training, which was commonly conducted by archery athletes during trainings. The sample received the treatment for 4 weeks (12 training sessions) and 2 tests (initial and final tests).

The experimental group received training treatment using NeuroTracker technology in a training room prepared according to the NeuroTracker Manual training protocol. The exercise was carried out in a quiet and relatively dark room. Each athlete used 3D glasses to activate the perception of visual acuity on the TV screen. The athletes were instructed to sit upright in a chair placed in front of a 50-inch 3D projection TV (LG) screen, while the seat was placed $1.33 \mathrm{~m}$ from the TV screen. In this study, researchers focused on Core session training. Each session was carried out for 8 seconds with 20 repetitions in one training meeting. Meanwhile, in the conventional training group, the athletes received treatment through exercises that were commonly performed during the routine training, such as warm-up, shadow shooting exercises without bows, concentration exercises by staring at the fire at a burning candle and staring and following the clockwise motion, and shooting at a predetermined distance in a training program.

To observe the shooting performance of the archery athletes, the test used an archery shooting ability test instrument at a 30 meter distance [8]. Furthermore, the obtained data were then processed and analyzed using the t-test with the help of SPSS version 24 for windows [9].

\section{Results and Discussion}

\section{Results}

Data were collected through a measurement process, then processed and analyzed using a statistical approach. The data analyzed in this study were the archery athlete shooting ability data. The calculation results are presented in Table 1. 
Table 1. Descriptive Statistics

\begin{tabular}{cccc}
\hline & & $\begin{array}{c}\text { Mean } \pm \text { Std. } \\
\text { Deviation }\end{array}$ & $\begin{array}{c}\text { Gain } \\
\text { Score }\end{array}$ \\
\hline $\begin{array}{c}\text { Experimental } \\
\text { Group }\end{array}$ & Pre-Test & $265.70 \pm 24.85$ & 32.90 \\
& Post-Test & $298.60 \pm 21.77$ & \\
\cline { 2 - 4 } Control Group & Pre-Test & $259.80 \pm 13.84$ & 19.70 \\
& Post-Test & $279.50 \pm 12.18$ & \\
\hline
\end{tabular}

Table 1 shows that both the experimental group and the control group experienced an increase in shooting performance after the treatment. In the experimental group, the initial test mean value was 265.70 with a standard deviation of 24.85 . In the final test, the average value was 298.60 with a standard deviation of 21.77 . It indicated that, there was an increase (32.90) in the experimental group. Furthermore, in the initial test, the control group obtained an average value of 259.80 with a standard deviation of 13.84. Meanwhile, in the final test, an average value of 279.50 was obtained with a standard deviation of 12.18 . The control group also experienced an increase. However, the increase (19.70) was not as high as the increase of the experimental group.

Furthermore, in determining the statistical test to be used, the normality and homogeneity tests were administered on the shooting performance variable data. Based on the results of the normality and homogeneity calculations, the pre-test and post-test data of the experimental and control groups gained $\mathrm{p}$ value $>0.05$, hence the data were declared normal and homogeneous. Therefore, the hypothesis test in this study used a parametric statistical test, namely the t-test.

The results of the hypothesis testing using the t-test, specifically paired t-test, are shown in Table 2.

Table 2. Hypothesis Testing

\begin{tabular}{ccc}
\hline & t Score & Sig. (2-tailed) \\
\hline Experimental Group & 11.961 & 0.000 \\
Control Group & 9.229 & 0.000 \\
\hline
\end{tabular}

Table 2 shows the results of hypothesis testing using the Paired Sample Test. The experimental group obtained a t-count value of 11,961 with a Sig. (2-tailed) of 0.000 $<0.05$. It indicates that there was a significant effect of NeuroTracker training on the archery athlete shooting performance. The control group obtained a t-value of 9,229 with a Sig. (2-tailed) of $0.000<0.05$. It indicates that there was also a significant effect of conventional training on the archery athlete shooting performance. To find out better exercise, the independent t-test was carried out. The calculation results obtained a $\mathrm{t}$ value of 3.791 and a significance value of $0.01<0.05$. Because the $\mathrm{P}$ value ( $\mathrm{Sig}$. 2 -tailed) $<0.05$, Ho is rejected. Therefore, it concludes that there was a difference in the archery athlete shooting performance between those trained with the NeuroTracker training and the conventional training. The group of athletes trained with NeuroTracker training performed better shooting performance improvement than the group of athletes trained with conventional training.

\section{Discussion}

The results of this study indicate that there was a significant effect of the NeuroTracker training on the archery athlete shooting performance. A significant effect also occurred in the group receiving the conventional training. Although both of the groups experienced a significant effect, the experimental group had a greater influence value. For that reason, it indicates that the NeuroTracker training has a better effect than the conventional training on the archery athlete shooting performance. These findings are relevant to several studies conducted by experts that NeuroTracker exercise is a tool that has an influence on brain function that regulates perceptual processes of cognition [10]. Several studies conducted by psychologists explain that cognitive ability is an important source for achieving the athlete success [11].

Cognitive abilities, including concentration, are important for archery athletes, because archery athletes must focus on the target since the arrow is released [3]. NeuroTracker training is important for athletes to improve their cognitive functions in order to build the athlete's ability to focus. The athletes who have a good cognitive function will have an ability to regulate the ability to perceive information from the environment quickly and interpret the information to determine the movements they should do as the key to increase maximum performance [12], especially for archery athletes. Research conducted by a study explains that the perceptual-cognitive skills training program has the potential to improve the athletic performance [13]. The athletes will be quicker and more accurate in making decisions in performing their motion tasks. Archery athletes will have the ability to make decisions quickly and accurately in aiming and releasing arrows when the shot has been made at the target.

In archery, NeuroTracker technology is important to be implemented, because the athletes will have knowledge in understanding important aspects, specifically in psychological aspects that support the mastery of archery techniques and training methods, tool design, and athlete performance improvement [3]. Archery athletes, after receiving NeuroTracker training, will have the ability to focus their attention on a series of archery technique movements ranging from stance, set, nocking, set up, drawing, full draw, release, and follow through [14]. At the aiming and releasing arrow stages, athletes are required to have the courage to make decisions quickly, precisely, and accurately, especially when a bow is equipped with a clicker, which means that the athlete must quickly release the arrow.

In NeuroTracker training, the athlete ability to track objects directly with fast decision making and anticipatory response time is trained. Fast tracking speed is essential in 
almost all sports. In games, athletes must have a higher ability to recognize situations in the game, anticipate future events effectively, and make the best possible decisions while avoiding harmful mistakes [12]. NeutroTracker enables athletes to create more efficient eye movements and perform better in measuring attention [13].

In archery, the shooting consistency of an archery athlete is generally considered as an important determinant of a successful score [5]. If an archery athlete does not have a good shooting consistency, then the score obtained will not be optimal. The score achieved by an archery athlete is a quantitative assessment that determines the achievements of an archery athlete [15]. This shooting consistency can be stated as one of the skills that archery athletes absolutely should acquire. Archery sport skills are generally assessed from physical, psychological, biomechanical, and perceptual aspects [15]. Therefore, it is important for athletes to do exercises that involve all of these aspects. An analytical study suggests that an archery athlete, both as a group and an individual, is influenced by many variables simultaneously [16]. In the clinical aspect, the increase in archery ability is seen from the heart rate and brain mechanism [15].

Archery is considered as a static sport of independent competition that requires a high level of focus [15]. The level of focus owned by archery athletes will affect their shooting performance. The efficiency of shooting technique is evaluated by considering the archer's targeting performance and the achieved accuracy classification [15]. Good shooting technique is not enough for an archery athlete, because, in performing shooting techniques, athletes face various existing pressures. The presence or absence of pressure is considered as an important factor affecting the score, where pressure is considered as a psychological stressor that interferes with the skill performance [14]. Furthermore, pressure is a psychological stressor that is considered to have an effect on cognitive performances, thereby reducing the quality of decision-making behavior in moving activities [14], including shooting techniques for archery athletes. Therefore, the archery athletes really need the NeuroTracker training as a form of perception-cognitive training.

Perceptual-cognitive training exercises have a transfer effect to athletes [17]. Cognitive function and working memory are related to particular and core motor skills, whereas the sum of all cognitive skills is strongly correlated with motor skills [18]. Cognitive training (CT) aims to develop general domain mental abilities to support functions, such as decision making, multitasking, and performance under stress [19]. The effective use of CT may require more task-specific training targeting intermediate-level transfer effects. Training on a 3D tracking task leads to an increase in working memory [19], which helps athletes better remember and master shooting techniques in archery. Since more scientific research support the perceptual-cognitive training, the NeuroTracker technique is leading the way in the sport performance enhancement domain [20].

NeutroTracker Training (3D-MOT) is a perceptual-cognitive training system based on a 3D virtual environment. Research conducted by previous researchers showed that 10 3D-MOT training sessions could improve attention, visual information processing speed, working memory, and also lead to measurable changes in resting neuroelectric brain function [21]. The 3D-MOT could improve cognitive function in a healthy population, where the corresponding change in the brain function was being observed. The 5 week training with 3D-MOT demonstrated a strong effect on attention, working memory, and visual information processing speed measured by neuropsychological tests, while associated changes measured by qEEG were also observed [21]. Parsons et al. suggested that combining 3D-MOT with other types of cognitive intervention could yield better results. This opinion is in accordance with the results of this study which suggests that cognitive-perception training (CT) through a NeutroTracker training has a significant effect on the archery athlete shooting performance. Therefore, it is important for archery athletes who want to improve their shooting performance to do exercises that focus on the athlete brain, memory, and psychological functions.

\section{Conclusions}

Based on the results of data processing and analysis, the researchers described three conclusions, including (1) NeuroTracker training and conventional training had a significant effect on the archery athlete shooting performance; (2) NeuroTracker training had a greater effect than the conventional training on the archery athlete shooting performance; (3) NeuroTracker training provided a greater improvement than the conventional training on the archery athlete shooting performance.

In addition, the researchers provide several suggestions related to this research. For archery coaches, it is hoped that this psychological training technology will be used as a new method to enhance psychological training methods that must be integrated into a training periodization. It would be better if the coach is able to have this technology, so that the sport science approach can be applied to improve the athlete performance, especially in archery. For archery trainers, psychological training technology, in the form of NeuroTracker training, is expected to be provided in each training session to improve the archery athlete shooting performance. For archery athletes, it is hoped that this NeuroTracker training is carried out routinely in every training session, because this exercise helps improve the shooting performance. 


\section{Acknowledgment}

We would like to deliver our gratitude to the Head of Sport Coaching Education Study Program who helped us in this research so that it can be published as a scientific article. We would also deliver our gratitude to the archery coaches who permitted us so that this research could go well.

\section{REFERENCES}

[1] Weinberg RS, Gould D. Foundations of sport and exercise psychology. 4th ed. Human Kinetics; 2007.

[2] Komarudin. Psikologi Olahraga. PT. Remaja Rosdakarya; 2016.

[3] Lee K, De Bondt R. Total Archery. Gam Jeong-Dong, GimPo-City Republic of Korea: Samick Sport; 2005.

[4] Setyawatie W. Panahan dan Menembak Pecahkan Rekor Dunia Terbanyak di Asian Games 2018. Pikiran Rakyat 2018.

[5] Quan CH, Mohy-Ud-Din Z, Lee S. Analysis of Shooting Consistency in Archers: A Dynamic Time Warping Algorithm-Based Approach. J Sensors 2017;2017. https://doi.org/10.1155/2017/7471217.

[6] Martinez N. NeuroTracker Testing and Training. Exerc Sci Coll Educ Univ South Florida 2019. https://www.usf.edu/education/areas-of-study/exercise-scie nce/services/neurotracker.aspx.

[7] Fraenkel JR, Wallen NE, Hyun HH. How to Design and Evaluate Research in Education. 8th Ed. New York: Mc Graw Hill; 2012.

[8] Manazi MS, Nurhayati F. Pengaruh Penerapan Latihan Imagery Terhadap Hasil Tembakan Pada Jarak 30 Meter Ekstrakurikuler Olahraga Panahan Smp Negeri 02 Bakung Blitar. J Pendidik Olahraga Dan Kesehat 2013;1:454-8.

[9] Santoso S. Complete Guide to Mastering Statistics with SPSS 24. Jakarta: PT. Elex Media Komputindo; 2017.

[10] Moen F, Hrozanova M, Stiles T. The effects of perceptual-cognitive training with Neurotracker on executive brain functions among elite athletes. Cogent Psychol 2018;5:1-13. https://doi.org/10.1080/23311908.20 18.1544105 .
[11] Mann DY, Williams AM, Ward P, Janelle CM Perceptual-cognitive expertise in sport: A meta-analysis. J Sport Exerc Psychol 2007;29:457-78. https://doi.org/10.11 23/jsep.29.4.457.

[12] Mangine GT, Hoffman JR, Wells AJ, Gonzalez AM, Rogowski JP. VISUAL TRACKING SPEED IS RELATED TO BASKETBALL-SPECIFIC MEASURES OF PERFORMANCE IN NBA PLAYERS. J Strength Cond Res 2014;28:2406-14.

[13] Appelbaum LG, Erickson G. Sports vision training: A review of the state-of-the-art in digital training techniques. Int Rev Sport Exerc Psychol 2016;11:160-89. https://doi.org/10.1080/1750984X.2016.1266376.

[14] Takai H, Kubo Y, Araki M. Characteristics of shooting time of the world's top level male archery athletes. NSSU J Sport Sci 2012;1:8-12.

[15] Loh WP, Chong YY. Classifying the archery performance with conditional effects on angular and linear shooting techniques. J Telecommun Electron Comput Eng 2018;10:95-9.

[16] Tinazci C. Shooting dynamics in archery: A multidimensional analysis from drawing to releasing in male archers. Procedia Eng 2011;13:290-6. https://doi.org/10.1016/j.proeng.2011.05.087.

[17] Romeas T, Guldner A, Faubert J. 3D-Multiple Object Tracking training task improves passing decision-making accuracy in soccer players. Psychol Sport Exerc 2016;22:19. https://doi.org/10.1016/j.psychsport.2015.06.002.

[18] Scharfen HE, Memmert D. The relationship between cognitive functions and sport-specific motor skills in elite youth soccer players. Front Psychol 2019;10:1-10. https://doi.org/10.3389/fpsyg.2019.00817.

[19] Harris DJ, Wilson MR, Smith SJR, Meder N, Vine SJ. Testing the Effects of 3D Multiple Object Tracking Training on Near, Mid and Far Transfer. Front Psychol 2020;11:1-7. https://doi.org/10.3389/fpsyg.2020.00196.

[20] Combineto NFL, Faubert J, Psychology CS, Combine NFL, Athletics C, Division N, et al. NeuroTracker Mental Training the New Frontier for Sports Performance 2012. http://www.prweb.com/releases/2012/2/prweb9238426.ht $\mathrm{m}$.

[21] Parsons B, Magill T, Boucher A, Zhang M, Zogbo K, Bérubé S, et al. Enhancing Cognitive Function Using Perceptual-Cognitive Training. Clin EEG Neurosci 2016;47:37-47. https://doi.org/10.1177/1550059414563746. 